\title{
Passive element fault analysis at the last mile of the FTTH network in Malaysia
}

\begin{abstract}
The optical transceiver performance for GPON FTTH (OLTTx and ONURx) for 300 live subscribers at legacy area has been monitored hourly for a duration of four months. The optical performance is then plotted against its faults due to the passive element at the last mile of the GPON FTTH network. The results show that the fault rate for aerial type of fiber distribution (FDP) is higher $(1.3 \%)$ than building, street cabinet and underground FDP types. More than $65 \%$ of the faults are contributed by optical fibers (drop fibers) and the rest is due to fiber connectors. The optical power received (ONURx) spectrum shows three types of patterns before disconnection; sudden disconnection, fluctuation and degradation of ONURx. This study provides preliminary information necessary for developing the passive element fault prediction for GPON FTTH at the last mile of the network.
\end{abstract}

Keyword: GPON FTTH network; Optical fiber; Link loss; Optical transmit power: receive power; Passive elements; Signals degradation 